\title{
Evidence for Terror Management Theory II: The Effects of Mortality Salience on Reactions to Those Who Threaten or Bolster the Cultural Worldview
}

\author{
Jeff Greenberg \\ University of Arizona \\ Sheldon Solomon \\ Skidmore College \\ Mitchell Veeder \\ University of Colorado, Colorado Springs
}

\author{
Tom Pyszczynski \\ Abram Rosenblatt \\ University of Arizona \\ Shari Kirkland \\ University of Arizona
}

University of Colorado, Colorado Springs

\author{
Deborah Lyon \\ University of Arizona
}

\begin{abstract}
Three experiments were conducted to test the hypothesis, derived from terror management theory, that reminding people of their mortality increases attraction to those who consensually validate their beliefs and decreases attraction to those who threaten their beliefs. In Study 1, subjects with a Christian religious background were asked to form impressions of Christian and Jewish target persons. Before doing so, mortality was made salient to half of the subjects. In support of predictions, mortality salience led to more positive evaluations of the in-group member (the Christian) and more negative evaluations of the out-group member (the Jew). In Study 2, mortality salience led to especially negative evaluations of an attitudinally dissimilar other, but only among subjects high in authoritarianism. In Study 3, mortality salience led to especially positive reactions to someone who directly praised subjects' cultural worldviews and especially negative reactions to someone who criticized them. The implications of these findings for understanding in-group favoritism, prejudice, and intolerance of deviance are discussed.
\end{abstract}

One of the most destructive and perplexing problems facing contemporary society is the pervasive tendency of people to respond with hostility and disdain toward those who are different from themselves. This tendency to reject those who are different is well-documented in the literature on prejudice (e.g., Tajfel, 1982), the similarity-attraction relationship (for a review, see Byrne, 1971), and reactions to deviance (e.g., Miller \& Anderson, 1979; Schachter, 1951). A common notion in much of the theorizing concerning these effects is that people prefer similar others over dissimilar others because of the consensual validation of one's own beliefs and attitudes provided by similar others (e.g., Byrne, 1971; Festinger, 1954; Tajfel, 1982).

The research reported in this article was concerned with the psychological basis of this need for consensual validation. More specifically, these studies tested several hypotheses derived from terror management theory (Greenberg, Pyszczynski, \& Solomon, 1986; Solomon, Greenberg, Pyszczynski, 1989, in press) concerning the anxiety-buffering function of cultural worldviews, the effects of mortality salience on the need for validation of these views, and the implications of this analysis for reactions to those who are different.

Terror management theory is based largely on insights

Correspondence concerning this article should be addressed to Jeff Greenberg, Department of Psychology, University of Arizona, Tucson, Arizona 85721. gleaned from Ernest Becker's (1962, 1973, 1975) attempts to synthesize the various social science disciplines into a general theory of human social behavior. ${ }^{1}$ According to Becker, sophisticated human intellectual abilities lead to the awareness of people's vulnerability and ultimate mortality. This awareness creates the potential for paralyzing terror concerning the vast array of aversive experiences that are the eventual inevitability of death. As these abilities were evolving, cultural conceptions of reality began to emerge. The potential for terror put a press on evolving cultures such that any culture that was to survive needed to provide means of managing this terror. Thus, from a terror management perspective, one very important function of culture (although surely not the only one) is to provide a means of conceptualizing reality that allows for the possibility of equanimity in the face of human vulnerability and mortality. Put simply, people's beliefs about reality provide a buffer against the anxiety that results from living in a largely uncontrollable, perilous universe, where the only certainty is death.

Although there is great variability in the contents of the worldviews associated with any given culture, all such conceptions provide the universe with order, meaning, value, and the possibility of either literal or symbolic immortality. This is ac-

\footnotetext{
${ }^{1}$ A thorough exposition of terror management theory is presented elsewhere (Greenberg, Pyszczynski, \& Solomon, 1986; Solomon, Greenberg, \& Pyszczynski, 1989) and is beyond the scope of this article.
} 
complished largely by providing a context within which individuals can acquire a sense of value or self-esteem. Cultural worldviews are structured so that protection from negative outcomes and a sense of immortality depend on fulfilling the cultural requirements for being valued. From this perspective, then, the cultural anxiety-buffer consists of two components: (a) faith in the validity of a cultural conception of reality that provides meaning, standards of value, and the promise of immortality, and (b) the belief that one is meeting or exceeding those cultural standards of value. The present research is concerned with reactions to those who bolster or threaten the cultural worldview component of the cultural anxiety-buffer. ${ }^{2}$

Because the cultural anxiety-buffer is by its very nature a fragile social construction (cf. Becker, 1962; Berger \& Luckmann, 1967; Goffman, 1959), it requires continual bolstering. This research focuses on two major sources of threat to the cultural worldview component of the buffer. First, people are constantly reminded of their vulnerability and mortality; one need only pick up a newspaper or turn on a television news program to find examples of such reminders of the fragile nature of human existence. Second, the diverse array of beliefs and values that are encountered provide a reminder that one's worldview may not be valid in any absolute sense, highlighting the tenuous nature of the cultural anxiety-buffer and contributing to the need for ongoing bolstering and protection from threat. To the extent that people need to believe that one and only one conception of reality is ultimately correct, the existence of conceptions at variance with their own implies that someone must be mistaken. Given the vital terror management function served by these conceptions, we suggest that the existence of others with different worldviews therefore increases the individual's need for validation of his or her own worldview.

The cultural anxiety-buffer is maintained largely through the consensual validation provided in cultural rituals and informal interactions with others (cf. Festinger, 1954). When people's beliefs and evaluations of themselves are shared by others, it increases the confidence with which those beliefs and evaluations are held; when other people disagree in these critical beliefs, it threatens their confidence. From an attribution theory perspective (e.g., Kelley, 1967), when others agree it provides a high level of consensus for the belief, which implies that the belief is externally determined and not a result of personal bias or perspective. Thus, as Byrne (1971) and others have suggested, attraction to similar others can be explained as resulting from the consensual validation of beliefs that such others provide. From a terror management perspective, then, positive reactions to similar others and negative reactions to dissimilar others occur partly because of the impact such individuals have on faith in one's worldview.

If reactions to others depend on the implications of agreement and disagreement for an individual's worldview, and if people's beliefs need to be defended because of the anxietybuffering function that they serve, then it follows that reminding people of what they are most frightened of should increase their tendency to respond positively to those who are similar and negatively to those who are different. Thus, reminding people of their mortality should increase the positivity of evaluations of those who bolster the cultural worldview and the negativity of evaluations of those who threaten it.
Initial evidence supporting this proposition has recently been obtained in a series of six studies by Rosenblatt, Greenberg, Solomon, Pyszczynski, and Lyon (1989). In five of these studies, mortality salience was manipulated by having subjects fill out a mortality questionnaire that asked them to describe what will happen to them as they physically die and what the thought of their own death arouses in them. Rosenblatt et al. found that mortality salience encourages unfavorable treatment of a moral transgressor (a prostitute) and favorable treatment of a heroic individual. They also found that these effects were not mediated by affect, self-awareness, or physiological arousal; in fact, the mortality salience manipulation used in these studies did not influence measures of affect and physiological arousal. According to terror management theory, heroes validate the cultural worldview by upholding cherished values, whereas moral transgressors implicitly reject the individual's cultural worldview by violating cherished values. In support of this interpretation, mortality salience encouraged negative reactions to the prostitute only among subjects with relatively negative attitudes toward prostitution and did not affect evaluations of stimuli unrelated to the cultural worldview.

The purpose of the three studies presented here was to assess whether similar effects could be shown for reactions to targets who bolster or threaten the cultural worldview in other ways. In all three studies, we used the same mortality salience treatment used in five of the Rosenblatt et al. (1989) studies. Study 1 concerned reactions to in-groupers and out-groupers; Study 2 dealt with reactions to attitudinally similar and dissimilar others; and Study 3 focused on reactions to those who explicitly criticize or praise the culture (for our subjects, the United States). Support for these hypotheses concerning reactions to others who in various ways can affect the cultural anxiety-buffer would provide converging evidence for terror management theory.

\section{Study 1}

One very common source of differences between people that has been recurrently linked to prejudice, conflict, and hostility is that of religious belief and affiliation. Throughout history, armed conflicts, ranging from minor skirmishes to full-scale wars, have been waged between the proponents of various religious conceptions of reality. Terror management theory (Greenberg et al., 1986; Solomon et al., 1989) posits that although specific political and economic considerations are certainly involved, enthusiasm for such conflicts among those who actually end up doing the killing and the dying is largely fueled

\footnotetext{
${ }^{2}$ Although the theory emphasizes the cultural roots of the worldviews held by any given individual, this does not imply that all individuals within a given culture will hold the same beliefs. The individual's worldview emerges as a consequence of the socialization process and is heavily influenced by the various agents of the culture with which the individual has contact (e.g., parents, teachers, religious leaders, and peers). As a result of diversity in life experiences and influences, each individual forges out his or her own unique set of beliefs and values. Thus, although many core beliefs are shared by most members of a given culture (e.g., among Americans, that democracy is the best form of government), there is considerable diversity in beliefs and values within any given culture.
} 
by the threat implied to each group's cultural anxiety-buffer by the existence of the other group. Study 1 was therefore designed to assess the effects of mortality salience on reactions to those of similar and dissimilar religious backgrounds.

As suggested above, the mere existence of others with similar beliefs validates one's faith in one's cultural worldview and the mere existence of others with different beliefs threatens that faith. Thus, we hypothesized that mortality salience would increase liking for a member of one's own religious group (Christians) and decrease liking for a member of a religious out-group (Jews). ${ }^{3}$

\section{Method}

Subjects. Twenty-six female and 20 male Christian introductory psychology students participated in partial fulfillment of course requirements. Six additional subjects identified themselves as having Jewish parents; data for these six subjects were not used. Data from one additional subject were discarded because he expressed suspicion that the questionnaires were not really filled out by other subjects.

Procedure. Four or five subjects participated in each session. Subjects were told that the study concerned personality and attitude variables that affect the impressions people form of each other, and that they would accordingly fill out some personality questionnaires and then be given personality information supplied by two other subjects that they would use to evaluate those subjects. It was explained that to ensure privacy and control over the factors that affect impressions, they would work on the study in individual cubicles.

When subjects arrived at their cubicles, they filled out a "preliminary questionnaire packet" that contained background, attitude, and personality questionnaires. This preliminary packet also contained the mortality salience manipulation for half of the subjects. The background questionnaire asked subjects for various sorts of demographic information, such as their age, sex, and number of siblings. More important, it also asked their parents' religious affiliations. This latter item was used to select subjects for inclusion in the study. Two filler questionnaires designed to resemble personality scales were then inserted. One of these questionnaires asked subjects to respond to 10 "Who am I?" questions, and was included because it was later used to reinforce the manipulation of the target's religious affiliation. Next, subjects filled out the JanisField self-esteem inventory (Eagly, 1967). Then they filled out a social issues survey that asked them to indicate on 10-point scales their level of agreement with 10 social issue statements such as "the decision about whether or not a pregnant woman should have an abortion should be left up to the woman and her doctor."

The mortality salience manipulation was placed at the end of the preliminary questionnaire packet. Subjects in the mortality salient condition filled out an additional questionnaire containing two open-ended questions. Specifically, they were asked to write about what will happen to them as they physically die and the emotions that the thought of their own death aroused in them. Roughly one-quarter page of space was provided for each item. Control subjects were not given this questionnaire. Although the control subjects in this study did not engage in a parallel writing task, Rosenblatt et al. (1989, Experiment 5) compared both a no-questionnaire control and a parallel writing task control and found no difference between the two but clear differences between each control group and a mortality salient group.

When subjects finished completing the questionnaires, the experimenter collected those materials, left, and then returned with the background questionnaire, the Who Am I? questionnaire, and the social issues questionnaire of two supposed male subjects. Subjects also received two sets of initial impressions assessments and an envelope. There were two versions of the set of questionnaires, with one version appearing to be filled out by a Jew and the other by a Christian.
The religious affiliation manipulation had two parts. On the background questionnaire, parents' religious affiliations were Jewish for both parents for the Jewish target and Methodist and Lutheran for the Christian target. In addition, on the Who Am I? questionnaire, the third response was either Jewish or Christian. The two versions involved relatively similar responses on the background questionnaire and the Who Am I? questionnaire; on the social issues questionnaire, one version tended to have politically liberal responses and one tended to have relatively conservative responses. Different attitudes were presented so that the targets would seem to be real, fairly different persons. Which set of questionnaires was apparently filled out by the Jew was counterbalanced. Order of consideration of the targets was also counterbalanced. Subjects were instructed to evaluate the subjects in a specific order and to fill out the first impression assessment as soon as they finished reading about the first subject. Thus, subjects rated each target immediately after reading the description of that person.

Each of the two initial impression assessments (one for each target) began by asking subjects to indicate their current mood. Subjects were asked to indicate on nine-point scales the extent to which they felt happy, calm, irritated, secure, angry, disturbed, hostile, and frustrated. This was followed by the Interpersonal Judgment Scale (Byrne, 1971), which asked subjects to rate the target's intelligence, knowledge of current events, mortality, adjustment, and the extent to which they would like and enjoy working with the target. Subjects were then asked to indicate (on a scale from $1=$ not at all applicable to $9=$ extremely applicable) how applicable each of 20 characteristics was to the target. The following traits were included because they fit the negative stereotype of Jews portrayed in anti-Semitic literature: stingy, manipulative, arrogant, snobbish, and obnoxious. The other 15 traits were honest, cheerful, reliable, trustworthy, argumentative, intelligent, warm, patient, kind, ambitious, stable, sleazy, introverted, spineless, and impulsive. Finally, subjects were told that to ensure anonymity, they should put the impressions assessments in the envelope, seal it, drop it in a box, and then return to the main room. When all the subjects returned to the main room, they were thoroughly debriefed.

\section{Results}

There were two counterbalanced variables: (a) which version of the questionnaire responses appeared to be Jewish, and (b) order of presentation (whether the Jew or Christian was evaluated first). Because data from non-Christians and the suspicious subject had to be discarded, neither of these variables was perfectly counterbalanced. It was therefore deemed important to include the counterbalanced factors in preliminary analyses of variance (ANOVAS) as between-group factors. These analyses revealed no influence of which target was presented as Jewish on the effects of mortality salience on evaluation of the targets. In contrast, order of presentation did show an influence on the effects of mortality salience on some evaluations of the targets. Therefore, the primary analyses to be reported were 2 (Mortality Salient vs. Nonsalient) $\times 2$ (Christian First vs. Jew First)

\footnotetext{
${ }^{3}$ In this study, Christians were used as the in-group because of their availability. Jews were chosen as the out-group for two reasons. First, although Jews have historically been one of the prime targets of prejudice, prejudice against Jews has been virtually ignored in the experimental social psychology literature. Second, there was a sufficient number of Jews on campus to have subjects evaluate a Jewish target without raising suspicion.
} 
between-subjects $\times 2$ (Christian vs. Jewish Target) within-subjects, unweighted means, least squares ANOVAs. ${ }^{4}$

Interpersonal Judgment Scale (IJS). The six items of the IJS were summed so that a high score indicated high attraction to the target. The three-way ANOVA on this variable revealed only the predicted interaction between mortality salience and target's religious background, $F(1,42)=8.39, p<.006$. The means for this interaction can be seen in Table 1. Planned pairwise comparisons showed that mortality salience increased attraction to the Christian, $t(44)=2.18, p<.05$, and decreased attraction to the Jew, $t(44)=2.08, p<.05$. In addition, the Christian was liked more than the Jew only in the mortality salient condition, $t(23)=3.36, p<.005$.

Trait applicability ratings. The 20 traits were summed so that a high score indicated positive trait ratings; this sum was then divided by 20 to form an overall trait index. A three-way ANOVA on this overall index revealed a marginal interaction between mortality salience and target, $F(1,42)=3.58, p<.07$. The means for this interaction, displayed in Table 1 , reveal a pattern similar to that found for the IJS, albeit weaker. Although mortality salient subjects, compared with control subjects, rated the Christian more positively and the Jew more negatively, the difference was significant only for ratings of the Christian, $t(44)=2.12, p<.05$. As with the IJS scores, the Christian was rated significantly more positively than the Jew only in the mortality salient condition, $t(23)=4.01, p<.001$.

Analysis of the overall trait rating index also revealed a marginal three-way interaction, $F(1,42)=3.96, p<.053$. The means for this interaction are displayed in Table 2. Pairwise comparisons indicated that the Christian was rated significantly more positively than the Jew only in the mortality-salientChristian-first condition, $t(14)=5.06, p<.001$. In addition, within the Christian-first condition, mortality salient subjects rated the Jew significantly more negatively than did control subjects, $t(44)=3.29, p<.005$. No other pairwise comparisons approached significance.

As noted earlier, the list of traits was chosen to include five traits that seemed to fit the negative stereotype of Jews; it was hypothesized that derogation of the Jew would be most likely to

Table 1

Mortality Saliency by Target Interaction on IJS Scores, the Overall Trait Index, and the

Nonstereotypic Trait Index: Study 1

\begin{tabular}{lcc}
\hline \multicolumn{1}{c}{ Target } & Mortality salient & Mortality nonsalient \\
\hline IJS scores & & \\
$\quad$ Christian & 30.25 & 27.73 \\
$\quad$ Jew & 26.46 & 28.86 \\
Overall trait index & & \\
Christian & 6.30 & 5.87 \\
$\quad$ Jew & 5.51 & 5.80 \\
Nonstereotypic trait index & & \\
Christian & 6.87 & 5.86 \\
Jew & 6.07 & 6.02 \\
\hline
\end{tabular}

Note. IJS = Interpersonal Judgment Scale. Means on the IJS could vary from 6 (low attraction) to 42 (high attraction). Means for overall and nonstereotypic traits could vary from 1 (negative evaluation) to 9 (positive evaluation).
Table 2

Three-Way Interaction on Overall Trait Index

and Negative Stereotype Trait Index: Study 1

\begin{tabular}{llllll}
\hline & \multicolumn{2}{c}{ Christian first } & & \multicolumn{2}{c}{ Jew first } \\
\cline { 6 - 7 } \cline { 5 - 6 } Target & $\begin{array}{c}\text { Mortality } \\
\text { salient }\end{array}$ & $\begin{array}{c}\text { Mortality } \\
\text { nonsalient }\end{array}$ & $\begin{array}{c}\text { Mortality } \\
\text { salient }\end{array}$ & $\begin{array}{c}\text { Mortality } \\
\text { nonsalient }\end{array}$ \\
\hline $\begin{array}{l}\text { Overall trait index } \\
\quad \text { Christian }\end{array}$ & 6.34 & 6.03 & & 6.22 & 5.76 \\
$\quad$ Jew & 5.08 & 5.90 & & 6.22 & 5.72 \\
Stereotypic trait index & & & & \\
$\quad$ Christian & 4.04 & 4.06 & & 3.48 & 3.58 \\
Jew & 5.67 & 3.89 & & 3.85 & 4.31 \\
\hline
\end{tabular}

Note. Means for the overall trait index could vary from 1 (negative evaluation) to 9 (positive evaluation). Means for the negative stereotypic trait index could vary from 1 (positive evaluation) to 9 (negative evaluation).

occur on those traits. Principal-components factor analyses of the 20 trait ratings were conducted for both targets to determine whether these traits would in fact emerge as a separate factor. The factor structures for both targets were quite similar, with two clear factors emerging. Using the criterion that to be used in a subscale, an item had to load .50 or better on the same factor for both targets, one subscale included the five designated negative stereotypic traits (snobbish, obnoxious, arrogant, manipulative, and stingy) and the trait "spineless." To form a negative Jewish stereotype index, these six items were therefore summed and divided by six, with a high number representing a negative stereotype. The other subscale included most of the other traits (honest, cheerful, trustworthy, warm, reliable, intelligent, patient, ambitious, kind, stable, and sleazy). To form a nonstereotypic trait index, these items were summed (with sleazy ratings reversed) and divided by 11 , with high values indicating a positive rating.

Analysis of the negative stereotype index did not yield the expected two-way interaction but did reveal a three-way interaction, $F(1,42)=4.90, p<.04$. As the means in Table 2 indicate, the expected assignment of greater negative stereotypic traits to the Jew in the mortality salient condition did occur, but only when the Christian was evaluated first. Pairwise comparisons showed that in the mortality-salient-Christian-first condition, the Jew was ascribed more negative stereotypic traits than the Christian, $t(14)=3.89, p<.002$, and more negative traits than the Jew in the control-Christian-first condition, $t(22)=$ $3.88, p<.001$. No other pairwise comparisons approached significance. Analysis of the nonstereotypic trait ratings did reveal a two-way interaction of mortality salience and target religious background, $F(1,42)=5.03, p<.03$, and no hint of the threeway interaction, $F<1$. As Table 1 indicates, for nonstereotypic traits, mortality salience enhanced ratings of the Christian but did not reduce ratings of the Jew. Specifically, in the mortality salient condition, subjects rated the Christian more positively

\footnotetext{
${ }^{4}$ In all three studies, initial analyses were conducted including sex as a factor. Sex did not interact with mortality salience on any of the primary dependent measures in any of the studies; thus, it was not included in the final analyses.
} 
Table 3

Means for the Mortality Salience by Order Interaction on Frustration Ratings: Study 1

\begin{tabular}{ccc}
\hline Assessment & Mortality salient & Mortality nonsalient \\
\hline First & 3.00 & 2.32 \\
Second & 3.79 & 2.18 \\
\hline
\end{tabular}

Note. Means could vary from 1 (not at all frustrated) to 9 (extremely frustrated).

than the Jew, $t(23)=3.15, p<.005$, and rated the Christian more positively than did subjects in the mortality nonsalient condition, $t(44)=3.85, p<.001$. No other pairwise comparisons approached significance.

Mood measures. Two (Mortality Salient vs. Control) $\times 2$ (Christian First vs. Jew First) between-subjects $\times 2$ (First vs. Second Mood Assessment) within-subjects ANOVAs were conducted on each of the eight affect scales. The only significant effects were a main effect of mortality salience on disturbed, $F(1,42)=4.19, p<.05$, and a Mortality Salience $\times$ Time of Assessment interaction on frustrated, $F(1,42)=4.77, p<.035$. Generally, mortality salient subjects reported being more disturbed than did control subjects, $M s=3.24$ and 2.23. The means for the interaction on frustrated are displayed in Table 3. Pairwise comparisons revealed that mortality salient subjects were more frustrated than control subjects at both the first and second assessment, $t(44)=2.19, p<.05$, and $t(44)=5.19, p<$ .001 , respectively. In addition, mortality salient subjects were more frustrated at the second assessment than at the first assessment, $t(23)=2.63, p<.05$.

To assess whether or not the effects of mortality salience on affect may have mediated the effects on the primary dependent measures, the original ANOVAs were repeated using the disturbed and frustrated ratings as covariates. ${ }^{5}$ If these emotions did mediate the target evaluations, then use of them as covariates should substantially reduce or eliminate the effects on the dependent measures.

In the first analysis of covariance (ANCOVA), the disturbed rating just prior to evaluation of the Christian was used as the covariate for ratings of the Christian and the disturbed rating just prior to evaluation of the Jew was used as the covariate for ratings of the Jew. This analysis yielded the same effects found previously on each dependent variable with virtually identical $p$-values. A similar ANCOVA was performed using frustrated ratings. For this analysis, all of the effects remained except for the three-way interaction on the sum of all the trait ratings, which was reduced to $p=.15$. Thus, there was some indication that frustration may have played a role in mediating that effect, but there was no evidence that it mediated any of the other effects.

\section{Discussion}

In general, the results of Study 1 supported terror management theory hypotheses. Inducing Christian subjects to think about their mortality led them to give more positive IJS ratings of fellow Christians and more negative IJS ratings of Jews. On the overall trait applicability ratings, these effects emerged primarily when the Christian was rated first. On the negative Jewish stereotype ratings, mortality salience again led to more negative trait ascriptions to the Jewish target only when the Christian was rated first. However, on the items not relevant to the negative Jewish stereotype, mortality salience increased the positivity of trait ascriptions to the Christian target regardless of who was rated first. Across all measures, the Christian was rated more positively than the Jew only in the mortality salient condition.

These findings are consistent with the notion that positive reactions to in-group members and negative reactions to outgroup members are mediated by the implications that such individuals have for the individual's cultural anxiety-buffer. According to terror management theory, beliefs about the nature of reality serve to buffer the anxiety that results from awareness of human vulnerability and mortality. Reminding subjects of their mortality increases their need for the anxiety-buffer provided by their beliefs and consequently increases the intensity of their reactions to those who bolster and threaten those beliefs.

Some of the effects of mortality salience on trait ascriptions depended on the order in which the two target persons were evaluated. Specifically, mortality salience decreased the favorability of trait ascriptions to the out-group member only when an in-group member had been previously evaluated. Perhaps the initial rating of the in-group member served to remind subjects of the particular dimension of their beliefs that was threatened by the out-group member.

Alternatively, rating the in-group member may have created an anchor against which ratings of the out-group member could be contrasted. Interestingly, a very similar explanation was offered for the results of a recent study by Struch and Schwartz (1989) that is relevant to our study in a number of ways. They found that aggression toward ultraorthodox Israeli Jews by other Israeli Jews was correlated with perceived conflict of interests and differences in basic values between the groups; in addition, these relationships were mediated by the degree to which subjects identified with their own group (in-group identification). The Struch and Schwartz findings thus indicate that only individuals who strongly subscribe to a particular worldview will react negatively to those perceived to have an antithetical alternative worldview.

Struch and Schwartz actually offered two explanations for these findings. The first is presented in the introduction of the article, where they argued that "if identification with own group is weak, intergroup conflict should motivate aggression less because the conflict is of little concern to the self" (p. 366). Although Struch and Schwartz offered no theoretical basis for this notion, it follows directly from the terror management idea that for those who subscribe to a particular group's worldview, group membership and values provide the basis for self-esteem (see especially Rosenblatt et al., Study 2, 1989).

The second explanation for the finding in question is offered in the discussion: "Respondents may have adopted a compara-

\footnotetext{
${ }^{5}$ For this and all of the other covariance analyses in this article, tests for homogeneity of within-group regression coefficients found no significant differences; thus, in each instance, the prerequisite assumption for analysis of covariance was met.
} 
tive perspective when rating . . . because they were asked to describe their own group's standing on each trait prior to rating the ultraorthodox. Rating the ingroup first may have served as a meaningful anchor for those highly identified with the ingroup, but not for those weakly identified" (p. 372). This claim cannot be evaluated within the context of Struch and Schwartz's procedure, as they did not vary the order in which subjects evaluated the in-group and out-group. However, our findings suggest that evaluating an in-group member first sometimes, but not always, encourages negative evaluations of outgroup members. In this study, in-group member evaluation led to derogation of the out-group member only when mortality was salient and primarily on ratings of the stereotypic traits. Clearly, further research on this phenomonon is needed.

A scarcity of non-Christian students prevented us from including students with religious backgrounds other than Christian in our sample. Although we doubt that the mortality salience effects are unique to Christians, this limits the generality of the findings. In addition, it is clear that religious affiliation is a type of group membership that seems especially relevant to coping with one's fear of death. Virtually all religions provide explanations for existence and beliefs about how death can be transcended. According to terror management theory, religious beliefs are one particularly important component of one's cultural anxiety buffer, but are certainly not the only component.

All central beliefs and attitudes serve a terror management function in that they provide a frame of reference for dealing with the world, a context within which a sense of value can be attained, and the possibility that one will be protected from aversive outcomes and be eligible for actual or symbolic immortality. Thus, it is important to demonstrate the effects of mortality salience on reactions to others who differ in areas other than religious affiliation. In an attempt to demonstrate broader generality of the mortality salience effect, in Study 2 we examined the effects of mortality salience on reactions to those with similar and dissimilar attitudes.

\section{Study 2}

Study 1 demonstrated that mortality salience increases the positivity of evaluations of in-group members and the negativity of evaluations of out-group members. From a terror management perspective, it is the consensual validation that membership in such groups implies, rather than group membership per se, that is responsible for producing such effects. Analogous reactions to similar and dissimilar others would therefore be expected even if the basis for comparison did not involve group membership. More specifically, the theory predicts that mortality salience should intensify the similarity-attraction relationship (Byrne, 1971), leading to greater liking for similar others and less liking for dissimilar others. Study 2 was designed to test this hypothesis.

Perhaps more important, Study 2 also addressed potential individual differences in interpersonal responses to mortality salience. From a terror management perspective, many personality characteristics can be viewed as unique styles of coping with the existential dilemma. Just as individuals vary in the specific beliefs and values that make up their cultural worldviews, they also vary in their styles of bolstering their anxiety buffers and responding to threats. One personality characteristic that seems particularly relevant to reactions to similar and dissimilar others is that of authoritarianism.

According to Adorno, Frenkel-Brunswick, Levinson, and Sanford (1950), the authoritarian personality is a pattern of traits or generalized behavioral style characterized by high regard for authority, rigidity, conventionality, and contempt or disdain for those who are worse off. They viewed this pattern as an essentially defensive reaction to the fear of weakness, inferiority, and unacceptable sexual impulses. Terror management theory is generally compatible with Adorno et al.'s position on the defensive function of authoritarianism, but emphasizes the role that fear of death and vulnerability plays in promoting such rigidity and the role that rigidity plays in protecting worldviews against threat.

On the basis of the work of Adorno et al. (1950), we predicted that high authoritarians would be especially likely to respond to existential threat by derogating dissimilar others and reacting positively to similar others. Furthermore, to the extent that fear of death and vulnerability plays a central role in promoting authoritarianism, we predicted that differences between high and low authoritarians would be greater when mortality was made salient. $^{6}$

\section{Method}

Subjects. Subjects were 60 male and 107 female students enrolled in lower level psychology courses who received extra credit in their courses in exchange for their participation. Subjects were randomly assigned to conditions in a $2 \times 2 \times 2$ (High Authoritarianism vs. Low Authoritarianism $\times$ Similar vs. Dissimilar $\times$ Mortality Salient vs. Control) factorial design. Eleven subjects expressed high degrees of suspicion and were dropped from subsequent analyses. These suspicious subjects were approximately evenly distributed across conditions.

Procedure. Subjects participated in groups ranging in size from three to six. Upon arrival, subjects were led to individual cubicles and were told that the experiment concerned problem-solving behavior. Subjects were also told that there were two parts to the experiment: The first part would involve completing some questionnaires, and the second part would involve a problem-solving interaction with a randomly chosen partner. Subjects were then told that they would be randomly paired with another subject from the same session and that they would work with that person on the problem-solving task. Groups with odd numbers of subjects were told that one of the subjects would be randomly selected not to take part in the second half of the experiment.

After this explanation, subjects were given consent forms to sign and the experimental sessions began (although actually only the first part of the experiment took place). First, they received a packet containing a survey of attitudes and the F-scale (Adorno et al., 1950). The survey of attitudes was used for the attitude similarity manipulation. It was modeled after the personal attitudes questionnaire used by Byrne (1971) and

\footnotetext{
${ }^{6}$ Study 2 also included a manipulation of cooperativeness of the expected interaction with the target. We reasoned that cooperative relationships should foster positive evaluations of others and that competitive relationships should foster negative evaluations. Thus, mortality salience might be especially likely to increase positive reactions to similar others under cooperative conditions and to increase negative reactions to dissimilar others under competitive conditions. However, this manipulation of subjects' expectations was not effective; thus, this variable yielded no effects and will not be discussed further
} 
colleagues and consisted of 12 items concerning a variety of issues (e.g., discipline of children, sports, the role of women in society, and the university grading system). To facilitate our manipulation of subjects' partners' attitudinal similarity, subjects were simply asked to indicate whether they agreed or disagreed with each statement. Each subject's survey was used to construct a bogus survey supposedly filled out by their partner that appeared to be either quite similar (75\% item agreement) or quite dissimilar ( $25 \%$ item agreement) to the subject's own.

After completing the survey of attitudes, subjects filled out the Fscale. Upon completion of the first set of materials, the questionnaires used to manipulate mortality salience were distributed. Subjects were randomly assigned to fill out questionnaires concerning either death or their favorite foods. The death questionnaire was identical to that used in Experiment 1. The food questionnaire was used in the control condition and asked subjects to describe their favorite restaurant and why they liked their favorite ethnic food.

While subjects were completing these questionnaires, the bogus attitude surveys were prepared by an assistant. Upon completion of the mortality salience or eating questionnaires, these bogus surveys were distributed. Subjects were told that they would be allowed to view their partner's attitude surveys because people usually know a little about the people with whom they expect to interact. Subjects were randomly assigned to either the similar ( $75 \%$ agreement) or dissimilar (25\% agreement) condition. The experimenter was blind to this manipulation and to the mortality salience manipulation.

Subjects then filled out a final questionnaire containing measures of attraction to the target, perceived similarity, and current mood state. All items were rated on 11 -point scales $(1=$ not at all, $11=$ very much $)$. Attraction to subjects' partners was assessed with a modified version of the Interpersonal Judgment Scale (Byrne, 1971; IJS), on which subjects rated the adjustment, intelligence, knowledge of current events, and morality of the target, and how much they liked and wanted to work with the target. As a manipulation check, subjects were asked to rate how similar the target was to themselves. Finally, current mood state was assessed on a set of 10 mood adjectives (e.g., happy, jittery, and gloomy). After completing these measures, subjects were probed for suspicion and debriefed.

\section{Results}

A median split on the F-scale was used to divide subjects into high and low authoritarian groups.

Manipulation checks. A $2 \times 2 \times 2$ (Authoritarianism $\times$ Similarity $\times$ Mortality Salience) ANOVA performed on perceived similarity revealed only a main effect of the similarity manipulation, $F(1,144)=172.38, p<.0001$. Subjects in the similar condition rated the target as more similar to themselves than did subjects in the dissimilar condition, $M \mathrm{~s}=7.84$ and 3.59 , respectively.

Evaluation of partner. As in Experiment 1, a composite IJS index was computed by summing the individual items. An ANOVA was conducted on the IJS composite. A main effect for similarity was found, $F(1,145)=86.83, p<.0001$, such that subjects liked similar partners more than dissimilar partners, ( $M \mathrm{~s}=41.48$ and 30.13 , respectively). More important, the predicted Threat $\times$ Similarity $\times$ Authoritarianism interaction was also found, $F(1,145)=4.08, p<.05$. Relevant means can be found in Table 4. Tests for simple two-way interactions revealed significant Threat $\times$ Similarity interactions within the high authoritarian group, $F(1,145)=5.68, p<.05$, but not within the low authoritarian group, $F(1,145)=.34$, ns. Pairwise tests for simple main effects revealed that high authoritarians liked dis-
Table 4

Mean IJS Composite Scores: Study 2

\begin{tabular}{ccc}
\hline IJS Ratings & Similar & Dissimilar \\
\hline Low authoritarians & & \\
Mortality salient & 40.82 & 32.11 \\
Mortality nonsalient & 40.38 & 29.65 \\
High authoritarians & & \\
Mortality salient & 43.71 & 26.41 \\
Mortality nonsalient & 41.20 & 31.95 \\
\hline
\end{tabular}

Note. IJS = Interpersonal Judgment Scale. Values in the table reflect mean ratings on the IJS, with high numbers reflecting positive evaluations.

similar others less under mortality salient conditions than under control conditions, $t(37)=2.28, p<.03$. Although high authoritarians tended to like similar others more when mortality was salient than when it was not, this difference fell short of statistical significance, $t(39)=1.07$, ns. Low authoritarian subjects' liking for their partners was not significantly affected by the mortality salience manipulation in either condition. The only condition under which high authoritarians differed from low authoritarians was the mortality-salient-dissimilar-other condition, $t(43)=2.50, p<.05$. Specifically, high authoritarians were more negative than low authoritarians in their evaluations of dissimilar others only in the mortality salient condition.

Mood ratings. A mood composite, constructed by subtracting the sum of the negative items from the sum of the positive items, was subjected to a $2 \times 2 \times 2$ ANOVA, and no significant effects were revealed. The critical Threat $\times$ Similarity $\times$ Authoritarianism interaction on the IJS was then reanalyzed using the mood composite as a covariate. The results were the same as those reported earlier, $F(1,144)=4.18, p<.05$. Thus, as in Experiment 1, there was no evidence that mood mediated the effect of mortality salience.

\section{Discussion}

The results of this study support the hypothesis that mortality salience encourages high authoritarians to derogate dissimilar others. In fact, high authoritarians differed from lows in their reactions to dissimilar others only when mortality had been made salient.

Interestingly, mortality salience enhanced the rejection of dissimilar others in Study 2 only among high authoritarian subjects. Authoritarians are typically individuals with a high level of respect for authority, rigid and dogmatic views, and negative attitudes toward those who are different. Thus, it is not surprising that such persons were especially likely to respond to existential threat with an increase in their tendency to reject dissimilar others. Low authoritarians showed no hint of this tendency toward increased derogation of dissimilar others when mortality was salient.

This raises the possibility that low authoritarians may not be concerned with mortality or do not engage in terror management. Although possible, this seems unlikely for a number of reasons. First, there is evidence suggesting that anxiety about death is widespread, even among individuals who deny it on 
self-report measures (Alexander, Colley, \& Adlerstein, 1957; Templer, 1971). Second, we have found powerful effects of mortality salience in a variety of other studies (reported here and in Rosenblatt et al., in press) in which authoritarianism was not considered; it seems unlikely that these effects resulted only from the reactions of the high authoritarians in our samples.

Third, there are a number of other plausible explanations for why low authoritarians did not derogate dissimilar others when mortality was salient. One is that in the worldviews of low authoritarians, open-mindedness and tolerance of different opinions are probably highly valued. If mortality salience increases concern about upholding values, low authoritarians may have not reacted negatively to another with dissimilar attitudes because doing so would have violated other equally important or, perhaps more important, values. It may also simply be that fellow in-groupers implicitly share so many basic values that only very dogmatic individuals would really be threatened by ingroupers with different attitudes on the less than central issues considered here.

\section{Study 3}

The first two studies, along with the Rosenblatt et al. (in press) studies, showed effects of mortality salience on evaluations of individuals who indirectly validate or threaten parts of the subjects' cultural worldviews. In fact, the findings of these studies may be particularly interesting because they suggest that positive reactions to in-groupers and similar others and negative reactions to out-groupers and dissimilar others result in part from their implications for one's cultural worldview. If, as terror management theory posits, implicit validation and threat motivate these reactions, then we would expect mortality salience to have even stronger effects on reactions to those who directly validate or threaten aspects of subjects' cultural worldviews. The primary purpose of Experiment 3 was to test this possibility.

In Experiment 3, we again manipulated mortality salience. We then asked American subjects to read an interview in which the interviewee had extremely unfavorable, mixed, or extremely favorable views of the United States. It was predicted that mortality salient subjects would react especially negatively to the unfavorable interviewee and especially positively to the favorable interviewee.

A third independent variable was also included in this study, because we thought that the credibility and background of the interviewer might affect reactions to his remarks. For example, unfavorable comments about the United States might be more threatening if made by a highly respected American than if made by a communist; conversely, favorable comments about the United States might be more validating if made by the communist than if made by the highly respected American. In order to examine these hypotheses, half the subjects were told that the interviewee was a Nobel Prize-winning Harvard political scientist; the other half were told that the interviewee was the president of the American Communist Party.

\section{Method}

Subjects. The subjects were 70 male and 81 female American introductory psychology students who participated in partial fulfillment of a course research requirement.
Procedure. Subjects arrived in the lab in groups of four or five. They were seated so that they could not see each other's forms, which were already placed on each desk. Subjects were told that the study concerned the relationship between personality and political attitudes. It was explained that the study would include innovative new measures, including a projective personality measure and a political measure that involves reading and reacting to an interview concerning political views. The experimenter then passed out consent forms, which were signed and collected. The subjects were then told to proceed through the packet without looking forward or backward. They were instructed not to put their names on the forms so that they could be assured of total anonymity. The packet consisted of a cover page with a few background questions to bolster the cover story, the mortality salience manipulation, an interviewee credentials page, the interview, and the primary dependent measures assessing reactions to the interview. When everyone had finished, the subjects were probed for suspicion and thoroughly debriefed.

Mortality salience manipulation. The same questionnaire used in Studies 1 and 2 was used to heighten the salience of mortality. The control subjects were given an analogous form asking them to "briefly describe the emotions that the thought of food arouses in you" and "briefly describe your behavior and reactions while eating." This control condition has been used in one prior study (Rosenblatt et al., Study 5,1989 ).

Favorability of interview to the culture. Subjects read a one-page interview in which the interviewee evaluated the U.S. political system. The page heading made it appear that the interview had been copied from Political Science Quarterly. Three versions of the interview were developed on the basis of extensive pilot testing. The pro-U.S. version recognized economic inequalities and foreign policy mistakes but was generally positive, concluding that "In this country, the people and not the government will be the final judges of the value of what I have to say. That is what makes this country a great place in which to be a free thinker." The mixed version acknowledged the value of many parts of the U.S. system but focused extensively on the influence of the power elite on the system and on the economically motivated, amoral behavior of the United States abroad. It concluded that "Morality has absolutely nothing to do with our foreign policy. That's why the idea that the U.S. is a promoter of world democracy and freedom is a total sham. Q: So, if we're just operating according to economic interests, why do people bother to vote? A: Half the people don't. They know there's no point."

The anti-U.S. version was very similar to the mixed version except for the conclusion, which was extremely hostile to the U.S. government. It concluded that "Violent overthrow is the only way the people will ever wrest control of their own nation from the capitalist powerbrokers. Saddest of all, I believe this lofty goal can only be accomplished with the help of outside influence from other powerful nations."

Interviewee credentials. The page before the interview summarized the credentials of the interviewee. In addition, the interviewee's title and affiliation appeared in boldface near the top of the page on which the interview was printed. Half the subjects were told the interviewee was a Harvard political science professor who had won a 1984 Nobel Prize in political science. The other half were told he was the president of the American Communist Party and winner of the Karl Marx Citation for public service.

Dependent measures. Following the interview, the subjects were asked to indicate their emotional state at the current moment by writing a number from 1 (not feeling the emotions at all) to 9 (feeling the emotion a great deal) next to 24 emotion descriptors varying along dimensions of arousal and positivity. This measure was based on Izard's (1977) Differential Emotions Scale.

Then subjects were asked a series of eight questions to assess feelings about the interview and the interviewee, all with nine-point response scales. These were the primary dependent measures. Specifically, concerning the interviewee, subjects were asked to indicate how much they 
Table 5

Means for Mortality Salience by Interview Interactions on Liking and Agreement Factors and Disturbing Rating: Study 3

\begin{tabular}{lccc}
\hline & \multicolumn{3}{c}{ Interview } \\
\cline { 2 - 4 } \multicolumn{1}{c}{ Condition } & Negative & Mixed & Positive \\
\hline Liking & & & \\
$\quad$ Mortality salient & $9.42_{\mathrm{a}}$ & $13.77_{\mathrm{b}}$ & $17.79_{\mathrm{c}}$ \\
$\quad \begin{array}{l}\text { Mortality nonsalient } \\
\text { Agreement }\end{array}$ & $13.55_{\mathrm{b}}$ & $13.80_{\mathrm{b}}$ & $14.40_{\mathrm{b}}$ \\
$\quad$ Mortality salient & $10.96_{\mathrm{d}}$ & $16.14_{\mathrm{cg}}$ & $20.54_{\mathrm{f}}$ \\
$\quad$ Mortality nonsalient & $15.04_{\mathrm{e}}$ & $16.84_{\mathrm{eg}}$ & $17.72_{\mathrm{g}}$ \\
How disturbing & & & \\
$\quad$ Mortality salient & $5.92_{\mathrm{a}}$ & $5.18_{\mathrm{a}}$ & $2.29_{\mathrm{b}}$ \\
$\quad$ Mortality nonsalient & $4.85_{\mathrm{a}}$ & $4.68_{\mathrm{a}}$ & $3.36_{\mathrm{b}}$ \\
\hline
\end{tabular}

Note. High means indicate high liking and agreement and high ratings of the remarks as disturbing. For each measure, means that do not share a subscript differ at $p<.05$.

liked and would like to meet him, how much they would like to have him as an instructor, and how knowledgeable they felt he was. Concerning agreement with the interview, they were asked how much they agreed with the interviewee's opinions and how much truth they thought there was in what he had to say. Then subjects were asked how surprising and how disturbing the interviewee's remarks were. Finally, they were asked to briefly comment on the interviewee's ideas.

\section{Results}

Unless otherwise indicated, all measures were analyzed by 2 (Mortality Salience) $\times 3$ (Favorability of Interview to the Culture) $\times 2$ (Source) ANOVAS.

Primary dependent measures. The primary dependent measures consisted of six questions concerning liking for the interviewee and agreement with his remarks. Factor analysis of these six items and the two similarly formatted surprising and disturbing items revealed two factors: liking (how much they liked the interviewee, how much they would like to meet him, and how much they would like to have him as an instructor) and agreement (how knowledgeable he was, how much they agreed with his opinions, and how much truth there was in his remarks).

Analysis of the liking measure revealed a main effect of interview, $F(2,139)=6.79, p<.002$, and the expected Mortality Salience $\times$ Interview interaction, $F(2,139)=4.83, p<.01$. As Table 5 indicates, the more favorable the interviewee was to the culture the more subjects generally liked him. However, the interaction reflects the fact that this propensity occurred reliably only in the mortality salient condition. Within that condition, the positive interviewee was rated significantly higher than both the mixed interviewee and the negative interviewee, $t(48)=$ $2.31, p<.05$, and $t(50)=4.93, p<.001$, respectively. In addition, the negative interviewee was liked significantly less than the mixed interviewee, $t(44)=2.42, p<.05$. None of these comparisons approached significance in the mortality nonsalient condition, all $t s<1$. In addition, mortality salient subjects liked the positive interviewee more and the negative interviewee less than did mortality nonsalient subjects, $t(51)=2.02, p<$ .05 , and $t(49)=2.42, p<.05$, respectively. Unexpectedly, there was no evidence that the credentials of the communicator influenced the extent to which subjects liked him.

Analysis of the agreement measure revealed very similar effects: a main effect of interview, $F(2,139)=22.54, p<.001$, and the expected Mortality Salience $\times$ Interview interaction, $F(2,139)=7.21, p<.001$. As Table 5 indicates, the more favorable the interviewee's remarks, the more subjects generally agreed with him. For agreement, there was one significant pairwise comparison within the mortality nonsalient condition; the positive interviewee was agreed with more than the negative interviewee, $t(50)=2.13, p<.05$. However, as with the liking measure, in the mortality salient condition all three comparisons were significant. The positive interviewee was agreed with more than the mixed interviewee, $t(48)=3.41, p<.01$, who was agreed with more than the negative interviewee, $t(44)=$ $3.86, p<.01$. Of course, the positive interviewee was agreed with much more than the negative interviewee, $t(50)=9.48$, $p<.001$. In addition, mortality salient subjects agreed more with the positive interviewee and less with the negative interviewee than did mortality nonsalient subjects, $t(52)=2.25, p<$ .05 , and $t(49)=3.20, p<.01$, respectively. As with the liking measure, the credentials of the communicator had no effect on subjects' agreement with the communication.

Affect measures. There were two affect-related measures that followed the measures of liking for and agreement with the interviewee. These questions asked how surprising and disturbing the interviewee's remarks were. For surprising, there was a significant Interview $\times$ Interviewee Credentials interaction, $F(2$, $139)=7.19, p<.002$. The (not surprising) pattern of means in Table 6 indicates that the subjects tended to be surprised by the positive remarks when attributed to the communist and by the negative and mixed remarks when attributed to the Harvard professor.

In addition, there was a main effect of interview, $F(2,139)=$ $24.04, p<.0001$, and a Mortality Salience $\times$ Interview interaction, $F(2,139)=4.25, p<.02$, on ratings of how disturbing the remarks were. As Table 5 indicates, the subjects were generally less disturbed by the positive interview than by the other two interviews. The interaction seems to reflect two marginal trends in the data. Mortality salient subjects tended to rate the negative interview as more disturbing than did mortality nonsalient subjects, $t(49)=1.91, p<.10$. In contrast, mortality salient subjects tended to rate the positive interview as less disturbing than did mortality nonsalient subjects, $t(51)=1.96, p<.10$.

To assess any possible mediating effect of feeling disturbed on the primary dependent measures, an ANCOVA was con-

Table 6

Means for Interview by Interviewee Interaction on Surprising Ratings: Study 3

\begin{tabular}{lccc}
\hline & \multicolumn{3}{c}{ Interview } \\
\cline { 2 - 4 } \multicolumn{1}{c}{ Interviewee } & Negative & Mixed & Positive \\
\hline Communist & $4.17_{\mathrm{ab}}$ & $3.54_{\mathrm{b}}$ & $4.95_{\mathrm{a}}$ \\
Harvard professor & $5.33_{\mathrm{a}}$ & $5.30_{\mathrm{a}}$ & $3.81_{\mathrm{b}}$ \\
\hline
\end{tabular}

Note. High means indicate rating of the interviewee's remarks as highly surprising. Means that do not share a subscript differ at $p<.05$. 
ducted on agreement and liking using disturbed ratings as a covariate. This analysis revealed the same predicted interactions, both $p \mathrm{~s}<.05$, indicating that disturbed feelings did not substantially mediate those interactions.

A factor analysis of the direct emotion ratings revealed five factors (afraid, upset, sad, excited, and happy). The ANOVAs on these factors revealed only two effects involving mortality salience: a mortality salience by interview interaction on happy, $F(2,129)=4.64, p<.02$, and a three-way interaction on excited, $F(2,139)=3.78, p<.03$. ${ }^{7}$ Although the means for these interactions did not parallel the effects on the primary dependent measures, ANCOVAS on liking and agreement were conducted using the excited and happy measures as covariates. For all ANCOVAS, the predicted interactions remained significant, all $p s<.05$. Thus, the effects on affect did not in any substantial way mediate the interactions on the primary dependent measures.

\section{Discussion}

The results of Study 3 provided strong support for the hypothesis that mortality salience encourages positive reactions to someone who praises the culture and negative reactions to someone who sharply criticizes the culture. As in Rosenblatt et al. (in press), these effects did not seem to be mediated by affective responses to the manipulations. Whereas the primary hypotheses of Experiment 3 were clearly supported, contrary to expectations, the credentials of the interviewee did not alter the primary effects of mortality salience. The credentials had some impact on the subjects with regard to how surprised they were by the remarks. Thus, although the credentials were noticed, they had no effects on the liking and agreement variables.

The fact that the Harvard professor was not even liked more or agreed with more than the communist in general suggests a number of possibilities. One is that those particular credentials do not differentially influence liking or perceived credibility. Although it is unlikely that communists were well-liked and trusted by these subjects, perhaps they did not feel particularly positive about Harvard political scientists either. Indeed, the overall mean rating of the interviewee on the liking measure was only 13.89 on a scale ranging from 3 (extreme dislike) to 27 (extreme liking). Another possibility is that the vivid, compelling nature of the interviewee's remarks overwhelmed any potential effect of credentials. Finally, it may also be that the subjects went out of their way to be fair and to judge the interviewee on the merits of his remarks rather than his background. Clearly, only future research can conclusively determine why credentials did not have a greater impact here.

\section{General Discussion}

In three experiments, reminding subjects of their mortality influenced their evaluations of others with similar and dissimilar beliefs and attitudes. In Study 1, mortality salience led Christian subjects to make more positive evaluations of a fellow Christian and more negative evaluations of a Jew. When the Christian was rated first, mortality salience also led these subjects to ascribe more negative stereotypic traits to the Jewish target person. In Study 2, mortality salience led authoritarian subjects to more negative evaluations of a potential interaction partner whose attitudes on a broad range of topics were dissimilar to their own. In addition, it appeared that mortality salience had a catalytic effect on subjects' authoritarian personality tendencies in that high authoritarians were more rejecting of dissimilar others than were low authoritarians only when their mortality had previously been made salient. In Study 3, mortality salience encouraged positive reactions to one who praised the culture and negative reactions to one who criticized it.

These findings are generally supportive of terror management theory hypotheses. From this perspective, liking for others depends largely on the impact such persons have on one's cultural anxiety-buffer. Others with similar worldviews are liked because they provide consensual validation for the individual's own worldview. Others with dissimilar worldviews are disliked because they make salient the lack of consensus for the individual's beliefs and thus threaten faith in those beliefs. To the extent that worldviews buffer the anxiety that results from awareness of vulnerability and mortality, people should be especially motivated to obtain consensual validation of these beliefs when faced with reminders of their mortality. Consequently, liking for similar others is increased and liking for dissimilar others is decreased when mortality is made salient.

In Study 1, mortality salience affected the way Christian subjects evaluated Christian and Jewish target persons. These findings suggest that terror management may play a significant role in in-group favoritism and prejudice. If so, then terror management theory may help account for the historic role of Jews as victims of prejudice and discrimination. Jews have traditionally been viewed as having strong faith in a deviant worldview that reserves for themselves the role of cosmic hero; indeed, until 1948 , Jews were a minority group wherever they happened to live. It is perhaps not a coincidence, then, that Jews have been targets of prejudice wherever they have been, for their longstanding faith has typically been viewed as a serious threat to the cultural anxiety-buffers of the majority groups around them.

Religious background is one aspect of the individual's cultural worldview that is very explicitly tied to beliefs about death and the possibility of an afterlife. From a terror management perspective, religious beliefs are a very important component of the anxiety-buffering worldview, but are certainly not the only component. All important beliefs and values are tied to the overall conception of reality that makes it possible for the individual to maintain equanimity. Thus, the theory predicts that mortality salience should have similar effects on evaluations of others who differ with respect to other aspects of the value system.

Study 2 indicated that such increased rejection of others who differ merely on attitudinal dimensions may be especially prominent among individuals high in authoritarianism. From a terror management perspective, personality characteristics are conceptualized as habitual styles of responding to existential problems. The finding that high and low authoritarians' evaluations of their partners differed from the others only when mortality was made salient is consistent with this interpretation.

\footnotetext{
${ }^{7}$ Complete details concerning the effects on the affect measures are not presented here for the sake of brevity; they are, however, available from Jeff Greenberg upon request.
} 
This finding is generally consistent with Adorno et al.'s (1950) contention that the authoritarian personality is basically a defensive way of coping with threats. It also suggests that death and vulnerability may be issues with which authoritarians are especially troubled.

The first two studies concerned reactions to those who implicitly validated or threatened subjects' cultural worldviews. In Study 3, mortality salience intensified reactions of American subjects to one who directly attacked or supported faith in the cultural worldview. Indeed, in Study 3, reactions to the target depended exclusively on his view of the culture and not at all on his group status. Whether he was a legitimate in-group authority figure or a member of a deviant group had no impact on evaluations; in contrast, his remarks about the United States had a large effect, especially in the mortality salient condition. Similar to findings concerning the role of perceived values in prejudice (e.g., Byrne \& Wong, 1962; Rokeach \& Mezei, 1966), the implications of the other's behavior for one's cultural anxiety-buffer, rather than group membership per se, determined the individual's reaction to that person. Thus, terror management may play a role in both the promotion of nationalism and the censorship and persecution of those courageous or foolhardy enough to challenge central aspects of a popular worldview. The Ayatollah Khomeini's call for the death of an author critical of Islam (Salmon Rushdie, for his book Satanic Verses) is a recent example of such persecution that seems to fit the terror management conception rather well.

\section{Conclusions}

Terror management theory is an extremely broad perspective with diverse implications for understanding a wide range of social behaviors. The three studies reported in this article demonstrate the theory's potential for adding to the understanding of interpersonal and intergroup relations. The present research, along with that reported by Rosenblatt et al. (1989), provides support for some terror management hypotheses concerning interpersonal relations, and thereby suggests that it may be fruitful to explore the wide range of additional hypotheses that can be derived from the theory concerning both this and other traditional areas of social-psychological inquiry (see Solomon et al., 1989 , for other recent efforts to do so). In addition, the current findings suggest that refinements of the theory are needed regarding personality and situational variables that may influence how mortality salience affects interpersonal judgments.

Beyond these theoretical issues, the practical significance of our findings is clear. Mortality salience appears to increase ingroup favoritism, rejection of those who are different, and authoritarian tendencies. This suggests that whenever events heighten mortality salience (e.g., newspaper accounts of catastrophes or violence in intergroup and interindividual conflicts), in-group solidarity, out-group derogation, nationalism, religious extremism, prejudice, discrimination, and intolerance of deviance are likely to escalate. More generally, the findings are consistent with the oft-stated contention (e.g., Adorno et al., 1950; Allport, 1954; Becker, 1975) that prejudice and hostility toward those who are different may be one particularly costly means of coping with fears and insecurities.

\section{References}

Adorno, T., Frenkel-Brunswick, E., Levinson, D., \& Sanford, R. N. (1950). The authoritarian personality. New York: Harper.

Alexander, I. E., Colley, R. S., \& Adlerstein, A. M. (1957). Is death a matter of indifference? Journal of Psychology, 43, 277.

Allport, G. W. (1954). The nature of prejudice. Reading, MA: AddisonWesley.

Becker, E. (1962). The birth and death of meaning. New York: Free Press.

Becker, E. (1973). The denial of death. New York: Free Press.

Becker, E. (1975). Escape from evil. New York: Free Press.

Berger, P. L., \& Luckmann, T. (1967). The social construction of reality: A treatise in the sociology of knowledge. New York: Anchor Books.

Byrne, D. (1971). The attraction paradigm. New York: Academic Press.

Byrne, D., \& Wong, T. J. (1962). Racial prejudice, interpersonal attraction, and assumed disability of attitudes. Journal of Abnormal and Social Psychology, 65, 246.

Eagly, A. H. (1967). Involvement as a determinant of response to favorable and unfavorable information. Journal of Personality and Social Psychology Monographs, 7(3, Pt. 2), 1-15.

Festinger, L. (1954). A theory of social comparison processes. Human Relations, 7, 117-140.

Goffman, E. (1959). The presentation of self in everyday life. Garden City, NY: Doubleday Anchor.

Greenberg, J., Pyszczynski, T., \& Solomon, S. (1986). The causes and consequences of the need for self-esteem: A terror management theory. In R. F. Baumeister (Ed.), Public self and private self (pp. 189212). New York: Springer-Verlag.

Izard, C. E. (1977). Human emotions. New York: Plenum.

Kelley, H. H. (1967). Attribution theory in social psychology. In D. Levine (Ed.), Nebraska Symposium on Motivation (Vol. 15, pp. 192238). Lincoln: University of Nebraska Press.

Miller, C. E., \& Anderson, P. D. (1979). Group decision rules and the rejection of deviates. Social Psychology Quarterly, 42, 354-363.

Rokeach, M., \& Mezei, L. (1966). Race and shared beliefs as factors in social choice. Science, 151, 167-172.

Rosenblatt, A., Greenberg, J., Solomon, S., Pyszczynski, T., \& Lyon, D. (1989). Evidence for terror management theory I: The Effects of mortality salience on reactions to those who violate or uphold cultural values. Journal of Personality and Social Psychology, 57, 681690.

Schachter, S. (1951). Deviation, rejection and communication. Journal of Abnormal and Social Psychology, 46, 189-207.

Solomon, S., Greenberg, J., \& Pyszczynski, T. (1989). A terror management theory of the role of self-esteem in social behavior. Unpublished manuscript, Skidmore College, Saratoga Springs, New York.

Solomon, S., Greenberg, J., \& Pyszczynski, T. (in press). The critical role of self-esteem in adjustment: A terror management analysis. In C. R. Snyder \& D. R. Forsyth (Eds.), Handbook of clinical and social psychology: The health perspective. New York: Pergamon Press.

Struch, N., \& Schwartz, S. H. (1989). Intergroup aggression: Its predictors and distinctness from in-group bias. Journal of Personality and Social Psychology, 56, 364-373.

Tajfel, H. (1982). Social psychology of intergroup relations. In M. R. Rosensweig \& L. W. Porter (Eds.), Annual review of psychology (Vol. 33, pp. 1-39). Palo Alto, CA: Annual Reviews.

Templer, D. I. (1971). The relationship between verbalized and nonverbalized death anxiety. Journal of Genetic Psychology, 119, 211 214.

Received August 9, 1988

Revision received April 11, 1989

Accepted July 26, 1989 